\title{
WEAK COMPACTNESS IN LOCALLY CONVEX SPACES
}

\author{
by I. TWEDDLE
}

(Received 1 August, 1967)

1. Introduction. In [2], R. C. James proved that a weakly closed subset $X$ of a real Banach space is weakly compact if and only if each continuous linear form attains its supremum on $X$. He also extended the result to the locally convex case, and, in [5], J. D. Pryce gave a simplified proof of the general result that is recorded below for reference in the sequel.

THeоRem A. Let $E$ be a real separated locally convex topological vector space with dual $E^{\prime}$. Let $X$ be a subset of $E$ such that

(i) $X$ is $\sigma\left(E, E^{\prime}\right)$-closed,

(ii) the closed convex envelope of $X$ is $\tau\left(E, E^{\prime}\right)$-complete.

Then $X$ is $\sigma\left(E, E^{\prime}\right)$-compact if and only if, for each $x^{\prime} \in E^{\prime}$, there exists an $x \in X$ such that

$$
\left\langle x, x^{\prime}\right\rangle=\sup _{y \in X}\left\langle y, x^{\prime}\right\rangle \text {. }
$$

In this note, Theorem A is applied to give concise proofs of some results on weak compactness. In $\S 3$, a short proof of the theorem of Krein giving conditions for the weak compactness of the closed convex envelope of a weakly compact set is derived. In $\S 4$, a result on absolutely convex weakly compact sets is established, which yields, as a corollary, a generalisation of Rainwater's theorem on weak convergence of sequences. Finally, in $\S 5$, a short proof of the weak relative compactness of the range of a vector-valued measure in a quasi-complete space is given.

Throughout, the term " locally convex topological vector space " is contracted to "locally convex space".

2. Complex spaces. It is well-known that, if $E$ is a complex locally convex space, $E$ may also be considered as a real space $E_{R}$, and, in the separated case, if $E_{R}^{\prime}$ is the real dual, the topologies $\sigma\left(E, E^{\prime}\right), \tau\left(E, E^{\prime}\right)$ coincide with $\sigma\left(E_{R}, E_{R}^{\prime}\right), \tau\left(E_{R}, E_{R}^{\prime}\right)$ respectively [4, p. 276]. This allows the proofs of Theorems 1-3 below to be given only in the real case, where Theorem A may be applied.

3. Krein's Theorem. Grothendieck has given an elegant proof of this result using Lebesgue's theorem of dominated convergence, while Pták and Namioka have given combinatorial proofs (for the first two proofs, see [4], pp. 327-333, for the third, see [3], pp. 157160).

Here Theorem A is employed to give a. short proof.

THEOREM 1. (Krein) Let $E$ be a separated locally convex space and let $X$ be a $\sigma\left(E, E^{\prime}\right)$ compact subset of $E$. Then the closed convex envelope $Y$ of $X$ is $\sigma\left(E, E^{\prime}\right)$-compact if and only if $Y$ is $\tau\left(E, E^{\prime}\right)$-complete (a condition which is automatically satisfied if $E$ is quasi-complete). 
Proof. If $Y$ is $\sigma\left(E, E^{\prime}\right)$-compact, it is $\sigma\left(E, E^{\prime}\right)$-complete, and so $\tau\left(E, E^{\prime}\right)$-complete [7, p. 105, Corollary].

Conversely, suppose that $Y$ is $\tau\left(E, E^{\prime}\right)$-complete. Let $x^{\prime} \in E^{\prime}$, and let

$$
\alpha=\inf _{x \in X}\left\langle x, x^{\prime}\right\rangle, \quad \beta=\sup _{x \in X}\left\langle x, x^{\prime}\right\rangle .
$$

There exists $\bar{x} \in X$, such that $\left\langle\bar{x}, x^{\prime}\right\rangle=\beta$, since $X$ is $\sigma\left(E, E^{\prime}\right)$-compact. Now the image of $Y$ by $x^{\prime}$ is $[\alpha, \beta]$, and $\bar{x} \in Y$. Hence

$$
\left\langle\bar{x}, x^{\prime}\right\rangle=\sup _{x \in Y}\left\langle x, x^{\prime}\right\rangle .
$$

The result now follows from Theorem $\mathrm{A}$.

4. A result on absolutely convex compact sets. Let $E$ be a separated locally convex space with dual $E^{\prime}$, and let $\mathscr{A}$ be a family of subsets of $E^{\prime}$ such that

(i) every $X \in \mathscr{A}$ is $\sigma\left(E^{\prime}, E\right)$-compact and absolutely convex,

(ii) $\bigcup_{X \in \mathscr{A}} X$ spans $E^{\prime}$.

Let $F^{\prime}$ be the vector subspace of $E^{\prime}$ generated by the extremal points of the elements of $\mathscr{A}$. It follows, by the Krein-Milman Theorem [7, p. 138, Theorem 1], that $\left(E, F^{\prime}\right)$ is a dual pair.

THEOREM 2. The same absolutely convex subsets of $E$ are compact for the topologies $\sigma\left(E, E^{\prime}\right)$ and $\sigma\left(E, F^{\prime}\right)$.

Proof. Let $G^{\prime}$ be the $\tau\left(F^{\prime}, E\right)$-completion of $F^{\prime} . \quad G^{\prime}$ may be considered as a vector subspace of the algebraic dual $E^{*}$ of $E\left[7, \mathrm{p} .101\right.$, Theorem 1]. Let $X \in \mathscr{A}$, and let $Y$ be the $\sigma\left(G^{\prime}, E\right)$ closed absolutely convex envelope of the set $Z$ of extremal points of $X$. Then $Y \subseteq X$, since $X$, being $\sigma\left(E^{\prime}, E\right)$-compact, is $\sigma\left(E^{*}, E\right)$-closed.

Now, on a compact convex set, a continuous linear form attains its supremum at an extremal point of the set $[4$, p. 336, (9)], so that, for each $x \in E$,

Thus

$$
\sup _{x^{\prime} \in Y}\left\langle x, x^{\prime}\right\rangle \leqq \sup _{x^{\prime} \in X}\left\langle x, x^{\prime}\right\rangle=\sup _{x^{\prime} \in Z}\left\langle x, x^{\prime}\right\rangle \leqq \sup _{x^{\prime} \in Y}\left\langle x, x^{\prime}\right\rangle .
$$

$$
\sup _{x^{\prime} \in Y}\left\langle x, x^{\prime}\right\rangle=\sup _{x^{\prime} \in X}\left\langle x, x^{\prime}\right\rangle=\left\langle x, y^{\prime}\right\rangle \quad \text { for some } \quad y^{\prime} \in Z \subseteq Y \text {. }
$$

It now follows, by Theorem A, that $Y$ is $\sigma\left(G^{\prime}, E\right)$-compact, and so, by the Krein-Milman Theorem, $Y=X$. Thus, since $\bigcup_{X \in \mathscr{A}} X$ spans $E^{\prime}$, we have $F^{\prime} \subseteq E^{\prime} \subseteq G^{\prime}$.

Now the same absolutely convex sets of $E$ are compact for $\sigma\left(E, F^{\prime}\right)$ and $\sigma\left(E, G^{\prime}\right)[7$, p. 104, Corollary 3]. Hence, by the above, these sets (and only these absolutely convex sets) are compact for $\sigma\left(E, E^{\prime}\right)$. 
Corollary 1. Suppose that $x_{n} \rightarrow 0$ under $\sigma\left(E, F^{\prime}\right)$, and that $\left\{x_{n}\right\}$ is $\sigma\left(E, E^{\prime}\right)$-bounded. Then if $E$ is $\tau\left(E, E^{\prime}\right)$-sequentially complete, there is an absolutely convex $\sigma\left(E, E^{\prime}\right)$-compact set containing $\left\{x_{n}\right\}$.

Proof. For every $\tau\left(E, E^{\prime}\right)$-continuous seminorm $p$, there exists $m>0$, such that $p\left(x_{n}\right) \leqq m$ for all $n$. Then, if $\left(\lambda_{n}\right) \in l_{1}$, the space of sequences $\left(\xi_{n}\right)$ of scalars such that

we have

$$
\sum_{n=1}^{\infty}\left|\xi_{n}\right|<\infty
$$

$$
\sum_{n=1}^{\infty} p\left(\lambda_{n} x_{n}\right)=\sum_{n=1}^{\infty}\left|\lambda_{n}\right| p\left(x_{n}\right) \leqq m \sum_{n=1}^{\infty}\left|\lambda_{n}\right|<\infty,
$$

so that, by the sequential completeness of $E$, the mapping

$$
t:\left(\lambda_{n}\right) \rightarrow \sum_{n=1}^{\infty} \lambda_{n} x_{n}
$$

maps $l_{1}$ into $E$. Its transpose $t^{\prime}$ is defined by

$$
\left\langle\left(\xi_{n}\right), t^{\prime}\left(x^{\prime}\right)\right\rangle=\left\langle t\left(\left(\xi_{n}\right)\right), x^{\prime}\right\rangle=\sum_{n=1}^{\infty} \xi_{n}\left\langle x_{n}, x^{\prime}\right\rangle
$$

for all $\left(\xi_{n}\right) \in l_{1}, x^{\prime} \in E^{\prime}$. Thus $t^{\prime}\left(x^{\prime}\right)=\left(\left\langle x_{n}, x^{\prime}\right\rangle\right)$, and so, by the conditions on $\left(x_{n}\right), t^{\prime}$ maps $F^{\prime}$ into $c_{0}$, the space of sequences of scalars that converge to zero. Thus $t$ is continuous for the topologies $\sigma\left(l_{1}, c_{0}\right)$ and $\sigma\left(E, F^{\prime}\right)$.

Now, the unit ball $B$ of $l_{1}$ is $\sigma\left(l_{1}, c_{0}\right)$-compact. Hence $t(B)$ is an absolutely convex $\sigma\left(E, F^{\prime}\right)$-compact set containing $\left\{x_{n}\right\}$. But, by the theorem, $t(B)$ is also $\sigma\left(E, E^{\prime}\right)$-compact.

Corollary 2. (Rainwater's theorem [6]) $\left(x_{n}\right)$ is $\sigma\left(E, E^{\prime}\right)$-convergent to $x_{0}$ in $E$ if (and only if) it is $\sigma\left(E, F^{\prime}\right)$-convergent to $x_{0}$, and $\left\{x_{n}\right\}$ is $\sigma\left(E, E^{\prime}\right)$-bounded.

Proof. It may be assumed, without loss of generality, that $E$ is $\tau\left(E, E^{\prime}\right)$-complete, for, if $\hat{E}$ is the $\tau\left(E, E^{\prime}\right)$-completion of $E$, the same absolutely convex subsets of $E^{\prime}$ are compact for the topologies $\sigma\left(E^{\prime}, E\right)$ and $\sigma\left(E^{\prime}, E\right)$ [7, p. 104, Corollary 3], so that the family $\mathscr{A}$ also satisfies the conditions (i) and (ii) in the dual pair $\left(E, E^{\prime}\right)$.

Then $x_{n}-x_{0} \rightarrow 0$ under $\sigma\left(E, F^{\prime}\right)$, and $\left\{x_{n}-x_{0}\right\}$ is $\sigma\left(E, E^{\prime}\right)$-bounded, so that, by Corollary $1,\left\{x_{n}-x_{0}\right\}$ is $\sigma\left(E, E^{\prime}\right)$-relatively compact. Suppose that $\left(x_{n}\right)$ is not $\sigma\left(E, E^{\prime}\right)$-convergent to $x_{0}$. Then there is a $\sigma\left(E, E^{\prime}\right)$-neighbourhood $U$ of the origin, and a subsequence $\left(x_{n(k)}\right)$, such that, for all $k, x_{n(k)}-x_{0} \notin U$. But $x_{n(k)}-x_{0} \rightarrow 0$ under $\sigma\left(E, F^{\prime}\right)$, and $F^{\prime}$ separates the points of $E$. Thus the origin can be the only $\sigma\left(E, E^{\prime}\right)$-cluster point of $\left(x_{n(k)}-x_{0}\right)$, which gives a contradiction.

5. The range of a vector-valued measure. Let $E$ be a separated locally convex space with topology $\eta$ and dual $E^{\prime}$. Let $S$ be a set, and $\mathscr{M}$ a $\sigma$-ring of subsets of $S$. A function $\mathbf{m}$ defined on $\mathscr{M}$ and taking values in $E$, is called a vector-valued measure if, for every sequence $\left(X_{n}\right)$ of mutually disjoint elements of $\mathscr{M}$,

$$
\mathrm{m}\left(\bigcup_{n=1}^{\infty} X_{n}\right)=\sum_{n=1}^{\infty} \mathrm{m}\left(X_{n}\right)
$$


the series being unconditionally convergent (i.e. summable) in $E$ under $\eta$. It can be shown, by the Pettis-Orlicz Theorem, that $\mathbf{m}$ is then a vector-valued measure for all topologies of the dual pair $\left(E, E^{\prime}\right)$.

Let $R=\{\mathrm{m}(X): X \in \mathscr{M}\}$, the range of $\mathrm{m}$, and, for every $X \in \mathscr{M}$, let

$$
R(X)=\{\mathbf{m}(Y): Y \in \mathscr{M}, Y \subseteq X\} .
$$

In [1], R. G. Bartle, N. Dunford and J. Schwartz showed that if $E$ is a Banach space, and $\mathscr{M}$ a $\sigma$-algebra, then $R$ is $\sigma\left(E, E^{\prime}\right)$-relatively compact. This is generalised in Theorem 3. First is required the following

$\mathrm{P}_{\mathrm{ROPOSITION}}$. Suppose that the closed convex envelope of $R$ is $\tau\left(E, E^{\prime}\right)$-complete, and let $\xi$ be some topology of the dual pair $\left(E, E^{\prime}\right)$. Then in order that $R$ be $\xi$-relatively compact, it is (necessary and) sufficient that $R(X)$ be $\xi$-relatively compact for all $X \in \mathscr{M}$.

Proof. Let $\left(\mathrm{m}\left(X_{\mathrm{n}}\right)\right)$ be any sequence in $R$. Then, since

$$
X=\bigcup_{n=1}^{\infty} X_{n} \in \mathscr{M},
$$

$R(X)$ is a $\xi$-relatively compact set containing $\left\{\mathbf{m}\left(X_{n}\right)\right\}$. Hence $\left(\mathbf{m}\left(X_{n}\right)\right)$ has a $\xi$-cluster point in $E$. The result now follows by Eberlein's theorem [7, p. 110, Corollary, and 4, p. 316, $\left.\left(1^{\prime}\right)\right]$.

THEOREM 3. If the closed convex envelope of $R$ is $\tau\left(E, E^{\prime}\right)$-complete, $R$ is $\sigma\left(E, E^{\prime}\right)$-relatively compact.

Proof. By the Proposition, it is sufficient to show that $R(X)$ is $\sigma\left(E, E^{\prime}\right)$-relatively compact for all $X \in \mathscr{M}$.

Let $x^{\prime} \in E^{\prime}$. Then $x^{\prime} \circ \mathrm{m}$ is a finite signed measure on $(S, \mathscr{M})$. Let $X \in \mathscr{M}$ and let $X=X_{1} \cup X_{2}$ be a Hahn decomposition of $X$ with respect to $x^{\prime} \circ \mathbf{m}$, so that $x^{\prime} \circ \mathbf{m}$ is nonnegative on $X_{1},\left(-x^{\prime}\right) \circ \mathrm{m}$ is non-negative on $X_{2}$, and $X_{1} \cap X_{2}=\emptyset[8, \mathrm{p} .32,(14.1)]$.

Let $\bar{R}(X)$ denote the $\sigma\left(E, E^{\prime}\right)$-closure of $R(X)$; then

$$
\sup _{x \in \bar{R}(X)}\left\langle x, x^{\prime}\right\rangle=\sup _{x \in R(X)}\left\langle x, x^{\prime}\right\rangle=\sup _{\substack{Y \in X \\ Y \in \mathcal{M}}} x^{\prime} \circ \mathrm{m}(Y)=x^{\prime} \circ \mathrm{m}\left(X_{1}\right)=\left\langle\mathbf{m}\left(X_{1}\right), x^{\prime}\right\rangle .
$$

Thus by Theorem $A, \bar{R}(X)$ is $\sigma\left(E, E^{\prime}\right)$-compact, from which the result follows.

Remark. It is well-known that $R$ is always bounded; in fact the proof is implicit in the above. Thus the completeness requirements of the Proposition and of Theorem 3 are automatically satisfied if $E$ is quasi-complete.

I wish to thank both Professor A. P. Robertson and Dr. Wendy Robertson for many useful discussions leading to the presentation of this note.

\section{REFERENCES}

1. R. G. Bartle, N. Dunford and J. Schwartz, Weak compactness and vector measures, Can. J. Math. 7 (1955), 289-305.

2. R. C. James, Weakly compact sets, Trans. Amer. Math. Soc. 113 (1964), 129-140.

3. J. L. Kelley, I. Namioka et al., Linear Topological Spaces (Princeton, 1963). 
4. G. Köthe, Topologische Lineare Räume I (Berlin, Göttingen, Heidelberg, 1960).

5. J. D. Pryce, Weak compactness in locally convex spaces, Proc. Amer. Math. Soc. 17 (1) (1966), $148-155$.

6. J. Rainwater, Weak convergence of bounded sequences, Proc. Amer. Math. Soc. 14 (1963), 999.

7. A. P. Robertson and W. J. Robertson, Topological Vector Spaces (Cambridge, 1963).

8. S. Saks, Theory of the Integral, 2nd revised edition (New York).

UNIVERSITY OF GLASGOW

Glasgow, W.2. 